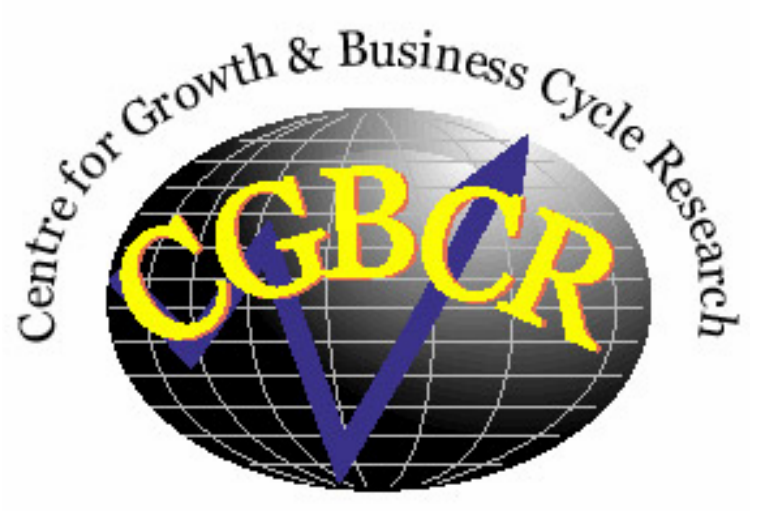

Discussion Paper Series

\title{
Corruption Clubs: Endogenous Thresholds in Corruption and Development
}

By

M. Emranul Haque and Richard Kneller

Centre for Growth and Business Cycle Research, Economic Studies,

University of Manchester, Manchester, M13 9PL, UK

November 2005

Number 067

Download paper from:

http://www.ses.man.ac.uk/cgbcr/discussi.htm 


\title{
Corruption Clubs:
}

\section{Endogenous Thresholds in Corruption and Development}

\author{
by
}

\author{
M. Emranul Haque and Richard Kneller
}

\begin{abstract}
The relationship between corruption and economic development is characterised by three stylised facts: (i) a strong negative correlation between corruption and development (ii) countries can remain trapped in high corruption-low development or low corruption-high development equilibria (iii) amongst intermediate levels of development corruption levels are more variable, some countries have high corruption and others low corruption. This paper argues that existing models are consistent with the first two only and demonstrates how these models might be extended to capture all three. The paper searches for the location of corruption clubs within the data and provides some explanation of their cause.
\end{abstract}

JEL Codes: D73, H26, O11

Keywords: Corruption, Public Spending, Thresholds, and Development.

\section{Corresponding Author:}

Dr. M. Emranul Haque

Lecturer in Macroeconomics

Economic Studies

School of Social Sciences

The University of Manchester

Phone: +44161275 4829

Fax: +44 1612754812

Email: Emranul.Haque@manchester.ac.uk 


\section{Corruption Clubs: Endogenous Thresholds in Corruption and}

\section{Development ${ }^{1}$}

\section{Introduction}

The economics of corruption has recently generated much interest in both the research and policy making communities. If one was to summarise the lessons that have been learnt from this literature the first, and perhaps the least surprising lesson, would be that there is a strong negative correlation between corruption and the level of development. This correlation is evident both anecdotally and at a more formal level. For example, outside of Italy, the often-mentioned outlier in this relationship, there are no examples of rich countries with high levels of corruption (corruption levels in Italy are in fact below the average for all countries), and no poor countries with low levels of corruption. Or more formally: if the level of corruption is regressed on the level of GDP per capita then, depending on the measure of corruption used, it is possible to explain between 50 to 75 per cent of the variation in the corruption index with this variable alone (Triesman, 2000). Evidence also exists for reverse causation between corruption and development; Mauro (1995) and Knack \& Keefer (1995) have for example, found evidence of a significant relationship between higher levels of corruption and lower rates of growth (of both output and capital investment). Indeed such is the strength of the relationship between corruption and development that both national governments and multilateral agencies have become concerned with reducing corruption levels in developing countries. ${ }^{2}$

However, while the negative correlation between corruption and the level of development is well established in empirical studies, ${ }^{3}$ the assumed linearity falls short of explaining the two additional stylised facts about the relationship between corruption and development described below. This paper shifts the focus to a non-linear negative relationship between corruption and development, develops a stylised dynamic general equilibrium model consistent with non-linearity, searches for the location of corruption clubs within the data and provides some explanations of their cause.

A second stylised fact that could be drawn from the existing literature would be that corruption levels are highly persistent across time. Some countries remain trapped in a 'bad' equilibrium, or what we might label corruption club, characterised by pervasive corruption and low development, whereas others end up in a low corruption, high-income equilibrium (Mauro, 2004). At the micro level, several authors have pointed to strategic complementarities as a major factor in determining the level of

\footnotetext{
1 The authors are grateful for the Leverhulme Trust for financial support (Grant No. F114/BF)

2 See for example the Extractive Industries Transparency Initiative set by the UK Government; the OECD 1997 Convention on Combating Bribery of Foreign Officials in International Business Transactions; or the recent addition (June 2004) of a $10^{\text {th }}$ principal of corporate behaviour to cover corruption by the UN

${ }^{3}$ See, among others, Mauro (1995) and Knack \& Keefer (1995), Ades \& Di Tella (1999), La Porta et al. (1999), Triesman (2000), Persson et al. (2001).
} 
corruption in the economy. The individual incentive to be corrupt depends on the behaviour of other agents in the economy and it is this corruption culture that gives rise to multiple equilibria. If corruption is pervasive then agents will choose to be corrupt also, whereas if others are generally honest then agents will choose not to be corrupt. A number of similar mechanisms have been used to generate this result. Andvig and Moene (1990) for example, assume that the probability a corrupt official will be reported to higher authorities is a decreasing function of the proportion of his colleagues who are also corrupt, while Sah (1991) explains differences in crime participation rates across otherwise similar societal groups on the basis of a learning model in which it is easier to observe members of one's own group, and Tirole (1996) the interaction between the reputation of a group and its individual members. Similarly Murphy et al (1993) have shown that aggregate returns to rent-seeking relative to market production is increasing until the proportion of rent-seekers to producers reaches an upper limit, while Putman (1993) has argued that a 'tragedy of commons' may explain the institutional and economic failure of some Italian regions. ${ }^{4}$

In contrast to the burgeoning micro literature, there remains relatively little macro research on this issue. One recent exception is the innovative analyses of Mauro (2004) using dynamic general equilibrium modelling of corruption and growth, where he explores two models of multiple equilibria in corruption and growth using the appropriation of funds by bureaucrats and politicians. The first model draws on the strategic complementarity developed in Andvig and Moene (1990) where if many people are corrupt the probability of any one individual being caught is low. Thus there will be a 'good' equilibrium characterised by absence of corruption and high rates of investment and growth, and a 'bad' equilibrium with pervasive corruption and low investment and growth. In the second model if a politician belongs to a government where the other politicians are very corrupt he would be more inclined to extract an even larger share of current output and to disregard any ensuing adverse effects on future output. This would happen because the politician expects to lose office when the citizens realise that economic growth has been harmed due to large appropriation.

On Figure 1 we plot both of these stylised facts. Figure 1 plots the mean and standard deviation of corruption against varying levels of development (where these are generated by ordering countries by their level of GDP per capita over the sample and then calculating a rolling mean/standard deviation of the surrounding 25 observations). ${ }^{5}$ Across the full range of development within Figure 1 the mean level of corruption has the expected negative relationship with GDP per capita - higher levels of development are associated with lower levels of corruption. ${ }^{6}$ Yet, this relationship is flatter at the tails - beyond a certain point the relationship between corruption and development changes. This is

\footnotetext{
${ }^{4}$ See also Cadot (1987), Dawid and Feichtinger (1996), and Huang and Wu (1994).

${ }^{5}$ Details on the corruption and GDP per capita data used can be found in Section 6 of the paper.
} 
also reflected in the standard deviation of corruption for the observations at the ends of the income distribution, which are low compared to the middle - these observations have very similar corruption scores. This would appear to match the idea that at the tails of the income distribution there are good and bad equilibria.

Figure 1: The mean and standard deviation of corruption at varying levels of GDP per capita

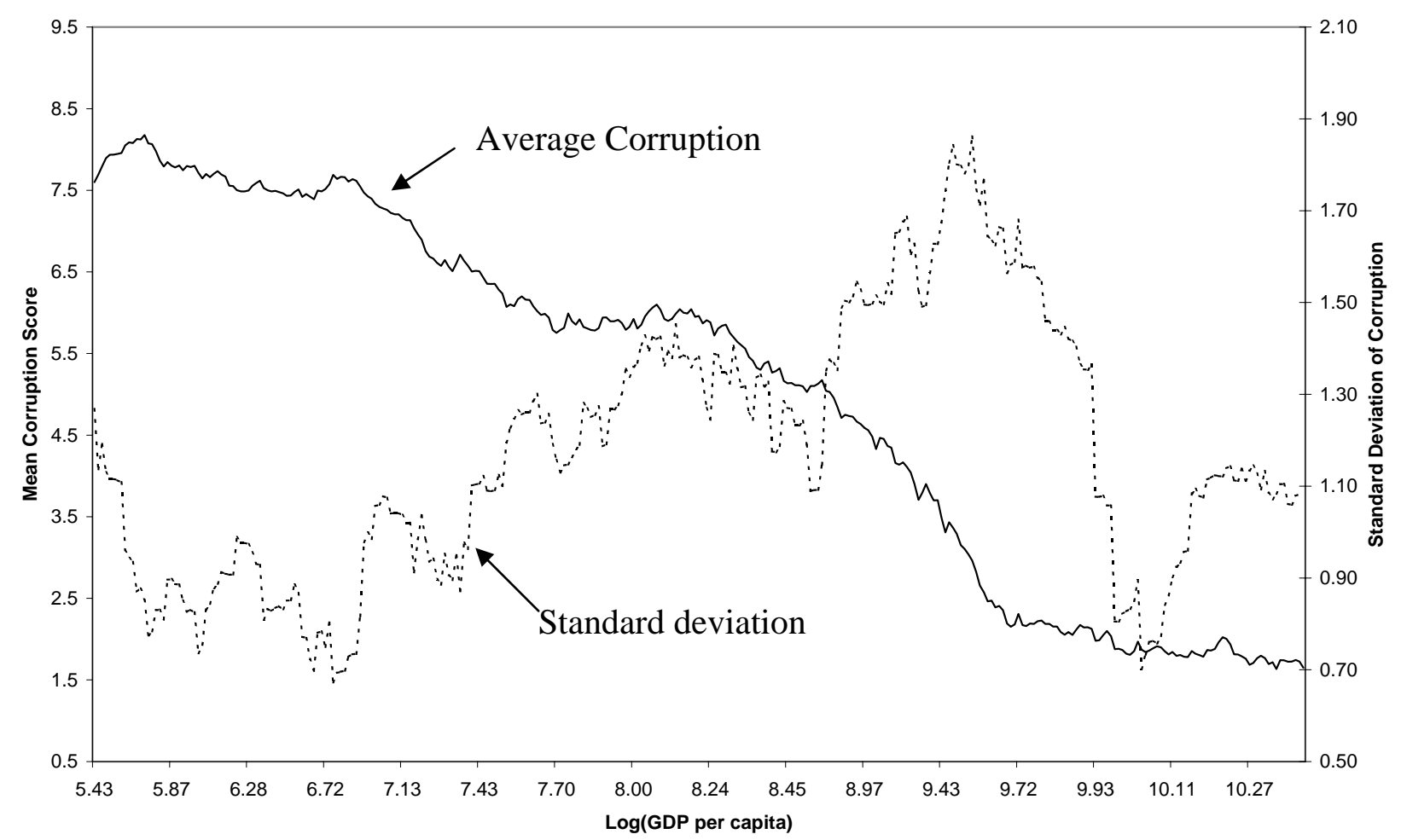

Figure 1 indicates the possibility of a third stylised fact between corruption and development however, one that is not posited by the recent theoretical literature described above. Across intermediate levels of development the level of corruption observed across countries is much more variable than in the tails of the development distribution. The standard deviation of corruption is low at both low and high levels of development and high at intermediate levels of development. This is not just driven by a low standard deviation at the ends of the distribution and occurs no matter how one looks at the data. The standard deviation of corruption for the first 25 per cent of observations ordered by their GDP per capita is 0.97 , across the next 50 per cent the standard deviation is 1.86 , and 1.14 for the final 25 per cent. Or to pick an example from the data; Argentina (2000-2003) and Singapore (1980-1985) are located next to each other on the ranking of income per capita (GDPpc of \$8,200 and $\$ 8,900$ respectively - at the $69^{\text {th }} / 70^{\text {th }}$ percentiles of GDP), yet Argentina has high corruption (a corruption score of 7.1 - in the top 30 per cent of corruption scores) and Singapore low corruption (a corruption score of 1.6 - in the bottom 10 per cent of corruption).

\footnotetext{
${ }^{6}$ There is a large empirical literature that confirms this negative correlation more formally using regression analysis, see for example Treisman (2000), Ades \& Di Tella (1999), La Porta et al. (1999), Persson et al. (2001).
} 
The standard deviation reaches a maximum and declines suddenly when the value of GDP per capita reaches about $\$ 17-18,000$. This drop in the standard deviation of corruption occurs as France (1988-92) enters and Italy (1995-97) drops out of the rolling calculation. This does not appear to be driven by Italy however, observations for Italy for the periods 1998-2000 and 2001-2003 remain in the data after this point. A final point of interest about this sudden decline in the standard deviation is that it is not matched by a similar decline in the mean value of corruption, across these observations the mean drops from 2.1 to 2 .

This paper considers how to extend an existing theoretical model to generate results consistent with this set of stylised fact, adopt an empirical methodology to determine the location of these corruption clubs in the data and finally explores their cause. Using a variant of the model of corruption with theft by Mauro (2004) we find (i) a two-way causal (negative) relationship between corruption and development, (ii) development traps arising from resource appropriated by public officials (iii) that corruption is more variable among countries at intermediate stages of development due to cultural differences (iv) and a change in culture leads to the collapse of the thresholds. We show that the existing bureaucratic culture (in the spirit of Andvig and Moene, $1990^{7}$ proxied by the probability of being caught and the fraction of corrupt bureaucrats) and culture in general (proxied by quality of public service and the difficulty in hiding illegal resources) can affect the thresholds.

We imagine an economy with government intervention, in which corruption arises because of an opportunity for bureaucrats to appropriate public funds when they are given the responsibility for providing productive public services. Such behaviour is risky since there is always a possibility that the government will detect it, in which case a bureaucrat will be dismissed from the job without pay. Such behaviour is costly to the society because it reduces the resources for public investment through which growth and development take place. A bureaucrat's expected gains and punishments from appropriating public resources depend on the level of economic development, as determined by the process of capital accumulation, which in turn, depends on the number of other bureaucrats who are also appropriating funds.

A key implication of our analysis is that, ceteris paribus, the higher the level of corruption (appropriation) the lower the wages of bureaucrats. Since incomes are lower as a result, a bureaucrat who is corrupt stands to lose less if he is caught so that the incentive to appropriate is stronger. In this way, a bureaucrat's appropriation of resources may depend critically on the appropriation of others hence the possibility of contagious behaviour and, with this, multiple equilibria. Below some critical level of capital, there is a low development regime where net gain of appropriating public resources is so high that the decision of any bureaucrat to be corrupt does not depend on other bureaucrats' 
appropriation. On the other hand, above a critical level of capital, a bureaucrat stands to be a net loser irrespective of others' decisions. But in the intermediate stages of development, whether the bureaucrat gains or loses from corruption depends on the other bureaucrats being corrupt. This feature gives rise to the existence of threshold effects and multiple development regimes.

To search for the location of corruption clubs in the data we use the endogenous threshold methodology of Hansen (2000). These models determine the location of corruption-GDPpc thresholds through changes in the estimated relationship between corruption and development in a regression framework. It also allows us to test for the significance of this threshold and provide a confidence interval around this estimate. We describe in some detail the location of these thresholds and the behaviour of countries that lie around these points. We find using this methodology that the relationship between corruption and development changes when GDP per capita reaches $\$ 215$ and again at $\$ 12,700$. There are three development-corruption clubs, one at very low-income levels, one at intermediate levels and one at high-income levels. We find that the evidence for the threshold between two of these clubs, the intermediate and high threshold, is not robust to the inclusion to either of two cultural variables, an indicator of democracy or British colonial heritage. This sensitivity does not occur for other cultural variables suggested by the existing empirical literature or for openness to international trade, all of which are themselves significantly correlated with corruption.

The remainder of the paper is organised as follows. In Section 2 we describe the model. In Section 3 we study the incentives of agents to engage in corruption. In Section 4 we establish the existence of multiple development regimes and the possibility of multiple corruption equilibria associated with different levels of development. In Section 5 we do some comparative static analyses to show that differences in the corruption-development relationships in different development regimes are attributed to some parameters related with culture. Section 6 describes the data being used and provides some initial evidence in support of the idea of thresholds in the data, while Section 7 describes the empirical methodology. Section 8 presents the empirical results and finally in Section 9 we offer some concluding remarks.

\section{The Model:}

Time is discrete and indexed by $\mathrm{t}=0, . ., \infty$. There is a constant population of two-period-lived agents belonging to overlapping generations of non-altruistic families. Agents of each generation are divided into two groups of citizens ${ }^{8}$ - private individuals (or households), of whom there is a fixed

\footnotetext{
7 This probability could also be a function of monitoring expenditure, rule of law, and better information flow due to higher competition, democracy or political stability. It may be noted, however, that all the above characteristics can reflect better culture in the economy.

8 We assume that agents are differentiated at birth according to their abilities and skills. A population of $m$ agents lack the skill necessary to become bureaucrats, while a population of $n$ agents possess these skills. The latter are induced to become bureaucrats by an allocation of talent condition established below.
} 
measure of mass $m$, and public officials (or bureaucrats), of whom there is a fixed measure of mass $n$. We assume that households are endowed with $\lambda>1$ units of labour and are liable to taxation, while the bureaucrats are endowed with only one unit of labour and are exempt from paying tax. Taxes are lump sum and are collected by bureaucrats on behalf of the government, which requires funding for public expenditures. Bureaucrats are labelled as corrupt when they choose to appropriate the public funds they have been given responsibility for by the government for the provision of public services. ${ }^{9}$ In doing this the bureaucrat expects to gain from appropriating public resources, leaving the economy with lower public services. All agents are risk neutral, working (and saving) only when young and consuming only when old. Production of output is undertaken by firms, which hire labour from households and rent capital from all agents. All markets are perfectly competitive.

The representative firm produces output, $y_{t}$, according to the following technology:

$$
y_{t}=A l_{t}^{\alpha} k_{t}^{1-\alpha} K_{t}^{\alpha} G^{\beta}, \quad A>0, \quad \alpha, \beta \in(0,1)
$$

where $l_{t}$ denotes labour and $k_{t}$ denotes capital. The firm hires labour from households at the competitively determined wage rate $w_{t}$ and rents capital from all agents at the competitively determined rental rate $r_{t}$. Firms also use the economy-wide capital as in Romer (1986) and the public good $G$ to enhance the efficiency of private production as in Barro (1990). Profit maximization implies that wage, $w_{t}=\alpha A l^{\alpha-1} k_{t}^{1-\alpha} K_{t}^{\alpha} G^{\beta}$. Since $l_{t}=l=\lambda m$ and $k_{t}=K_{t}$, we may write these conditions as

$$
w_{t}=\alpha A l^{\alpha-1} G^{\beta} k_{t}
$$

\subsection{The Government and Public Services}

We envisage the government as providing productive public services, which contribute to the efficiency of output production (e.g., Barro 1990). The government incurs expenditures on public goods (investment projects) and bureaucrats' salaries that are financed in each period by running a continuously balanced budget. Its revenues consist of lump sum taxes, $\tau_{t}$, collected by bureaucrats from households, plus any fines imposed on bureaucrats who are caught engaging in corruption.

Any bureaucrat can work for a firm, supplying one unit of labor to receive a non-taxable income equal to the wage paid to households. Any bureaucrat who is willing to accept a salary less than this wage must be expecting to gain through theft and is therefore immediately identified as being corrupt. As in other analyses (e.g., Acemoglou and Verdier 1998), we assume that a bureaucrat who is discovered to be corrupt is subject to the maximum fine of having confiscated all of his legal income

\footnotetext{
9 Bureaucrats are also responsible for the collection of taxes, an activity that may also be open to abuse in the form of bribery and tax evasion. This does not arise in our model because all households have the same income and are subject to same tax liability.
} 
(salary) (i.e., he is dismissed without pay) plus (at least) a proportion, $\delta$, of his illegal income ${ }^{10}$. Given this, then no bureaucrat would ever reveal himself in the way described above. As such, the government can minimise its labour costs, while ensuring complete bureaucratic participation, by setting the salaries of all bureaucrats equal to the wage paid by firms to households. ${ }^{11}$

We assume that one unit of public spending is transformed into one unit of productive public service. Each bureaucrat is provided with public fund $g$. If the bureaucrat does not appropriate the fund, then he spends the whole amount that he has been responsible for. In the case where all bureaucrats decide not to be corrupt (i.e., not to appropriate), then total public services that the government can provide for the output-producing firms is $\hat{G}=n g$. Conversely, if all the bureaucrats appropriate a fraction, $(1-\theta)<1$, of the public fund that they are responsible for, then the economy would end up with total productive public services, $\widetilde{G}=\theta n g .{ }^{12,13}$

\subsection{Agents}

Each young household of generation $t$ supplies inelastically $\lambda$ units of labour to a firm and earns a wage, $w_{t}$ Each household is liable to pay a lump sum tax $\tau$. In each case the household saves its entire net income after tax as (non-consumable) capital, which is rented to firms at the market rate of interest in order to finance old-age consumption.

\section{Bureaucrats}

Each young bureaucrat of generation $t$ is paid the salary $w_{t}$ for supplying inelastically his unit of labour endowment to the government. Each bureaucrat has $m / n$ households and one public good under his jurisdiction. His income depends on whether or not he is corrupt. Like all households, all bureaucrats save their entire income to finance old-age consumption.

A bureaucrat may or may not be corrupt. If the latter, then he expects to receive an income of $w_{t}$, as above. If the former, then his expected income depends on the fund that he appropriates and retains, the chances of being caught and the penalties incurred if he is exposed. Such a bureaucrat

\footnotetext{
${ }^{10}$ Here we use this $\delta$ only to capture the idea that if the rule of law is improved, the security is tightened, and a better information flow is experienced due to better political institutions (e.g., democracy), then it becomes difficult on the part of corrupt agents to hide their illegal earning.

11 This has the same interpretation as the allocation of talent condition in Acemoglou and Verdier (2000). The government cannot force any of the $n$ potential bureaucrats to actually take up public office, but it is able to induce all of them to do so by paying what they would earn elsewhere.

${ }^{12}$ For some cases, public spending may provide no productive public services. For example, it is reported in "Statesman", an Indian National Newspaper stated in 14 June 1993 that “... large craters in several important streets of Kolkata including Russel Street, Middleton Street, Sudder Street, Chowringhee Lane, Mirza Ghalib Street had been patched up with stone chips of such inferior quality that they turned to dust within two days of repair".

13 As public resources (spending) is one of the arguments in our production function, the loss of public resources $[$ i.e., $(1-\theta) n g]$ generates lower capital accumulation and hence lower economic growth under corruption regime in our
} 
engages in appropriation (theft) of public funds. Although the bureaucrat receives $g$ in public funds, he spends only $\theta g$, providing the economy with $\theta g$ amount of public services. Thus $(1-\theta) g$ is the amount of funds that a bureaucrat is able to steal. In general, corrupt individuals may try to remain inconspicuous by concealing their illegal income, by investing this income differently from legal income and by altering their patterns of expenditure. For simplicity, here we assume that a corrupt bureaucrat hides his income if he is to stand any chance of not being caught. By doing so, he can make sure that he can consume this illegal income when he is old. Due to imprecise government monitoring (that entails zero cost, for simplicity) ${ }^{14}$ with probability $p$, the bureaucrat may get caught and face punishment that we have mentioned before. Accordingly, his income is $w_{t}+(1-\theta) g$ with probability (1- $p$ ), and $(1-\delta)(1-\theta) g$ with probability $p$, implying an expected income of $(1-p) w_{t}+(1-p \delta)(1-\theta) g$.

\section{The Incentive to be Corrupt}

A corruptible bureaucrat will appropriate public funds if his expected payoff from doing so is no less than his payoff from not doing so. From the preceding analysis we may state this condition as

$$
(1-p) w_{t}+(1-p \delta)(1-\theta) g \geq w_{t}
$$

Rearranging, $\quad(1-p \delta)(1-\theta) g \geq p w_{t}$

Intuitively, a bureaucrat is more likely to be corrupt the more he expects to gain in illegal income and the less he expects to lose in legal income if he is caught. The key feature of this condition is that it depends on the economy-wide variable $w_{t}$. As we shall see the wage is determined by current events in the economy, which in turn is a function of the aggregate level of corruption at time $t$. This reflects the fact that higher wages of all agents, associated with higher levels of capital, imply higher costs to bureaucrats if they are caught being corrupt. This means that the incentive for each corruptible bureaucrat to be corrupt depends on the number of other such bureaucrats who are expected to be corrupt. Consequently, bureaucratic decision-making entails strategic interactions, which may result in multiple, frequency-dependent equilibria.

We begin to explore the above possibility by first studying the incentive of an individual corruptible bureaucrat to be corrupt under two possible scenarios - one in which no other corruptible bureaucrat is corrupt and the other in which all other corruptible bureaucrats are corrupt. In conducting the analysis, we make use of some of our earlier results and assumptions. Specifically, we recall that in equilibrium, $l_{t}=l=\lambda m$ and from (2), we have $w_{t}=\alpha A l^{\alpha-1} k_{t} G^{\beta}$. Thus, as indicated

model. As we are concerned about generating poverty traps and multiple equilibria, we do not report the growth and steadystate analysis. These are available upon request. 
above, $w_{t}$ is determined by the level of capital stock, $k_{t}$ and total public service, $G$, both of which are determined by the aggregate level of corruption.

Consider, then, the case where no bureaucrat is corrupt. Total government expenditure on public goods is $G=n g$, while the total public service acquired out of this spending is $\hat{G}=n g$. Under such circumstances, wage rate in (2) is $\hat{w}\left(k_{t}\right)=\alpha A l^{\alpha-1}(n g)^{\beta} k_{t}$ and the incentive condition in (3) becomes

$$
(1-p \delta)(1-\theta) g \geq p \hat{w}\left(k_{t}\right)
$$

For the case in which all bureaucrats are corrupt, the economy would acquire total public services, $\tilde{G}=\theta n g$. Under such circumstances, the wage rate in $(2)$ is $\tilde{w}\left(k_{t}\right)=\alpha A l^{\alpha-1} \theta^{\beta}(n g)^{\beta} k_{t}$ and the incentive condition in (3) becomes

$$
(1-p \delta)(1-\theta) g \geq p \widetilde{w}\left(k_{t}\right)
$$

Observe that, since $\theta<1$, it is easily verifiable that $\widetilde{w}\left(k_{t}\right)<\hat{w}\left(k_{t}\right):$ that is, for any given stock of capital, $k_{t,}$ wages are lower under corruption than under non-corruption. This follows from the fact that corruption reduces the total public services, $\tilde{G}<\hat{G}$. In doing so, it also reduces the productivity of labour in the production of output.

\section{Equilibria}

The foregoing analysis identifies the conditions for an individual bureaucrat to be corrupt, given that all other bureaucrats are corrupt or non-corrupt. It is also revealed that the extent to which the aggregate level of corruption influences aggregate economic outcomes - in particular, wages and the public services that could be utilised in output production. We now proceed to study how incidence of corruption is itself determined. As we shall see, whether or not corruption forms part of equilibrium depends on the level of development of the economy. In this way, our model predicts a relationship between corruption and development that is fundamentally two-way causal where corruption not only reduces growth but also is reduced as the economy develops.

The crucial conditions for determining equilibrium behaviour are given in (4) and (5). Note that both $\hat{w}\left(k_{t}\right)$ and $\tilde{w}\left(k_{t}\right)$ are increasing monotonically (linearly) in $k_{t}$. Note also that $\tilde{w}\left(k_{t}\right)<\hat{w}\left(k_{t}\right)$ for all $k_{t}$. Now Substituting values for $\hat{w}\left(k_{t}\right)$ and $\tilde{w}\left(k_{t}\right)$ in (4) and (5) we may identify two critical levels of capital, $k_{1}^{c}$ and $k_{2}^{c}$

\footnotetext{
14 The model could be extended straightforwardly to allow for costly monitoring without altering its main implications. To a large extent, our results would be strengthened in the sense that there would an additional loss of resources from corruption.
} 


$$
\begin{aligned}
& k_{1}^{c}=\Lambda\left[\frac{(1-p \delta)(1-\theta)}{p}\right] \\
& k_{2}^{c}=\Lambda\left[\frac{(1-p \delta)(1-\theta)}{p \theta^{\beta}}\right]
\end{aligned}
$$

where, $\Lambda=\frac{(\lambda m)^{1-\alpha} g^{1-\beta}}{\alpha A n^{\beta}}$. It is evident that $k_{1}^{c}<k_{2}^{c}$ and both depend on $p$ (probability of detection), $\theta$ (quality or productivity of public service, or the part of public spending that bureaucrat has not appropriated) and $\delta$ (the illegal resource that a bureaucrat finds difficult to hide), all of which can be changed by improving the rule of law. Better information flows can be achieved through improvements in the quality of political institutions (e.g., democracy) and political stability. These threshold levels of capital represent boundaries between regions where the incentive conditions in (4) and (5) are either satisfied or violated. We are now in a position to establish some key testable results, which we illustrate in Figure 2.

Equilibria: $\left[\hat{w}\left(k_{t}\right)>\tilde{w}\left(k_{t}\right)\right]$

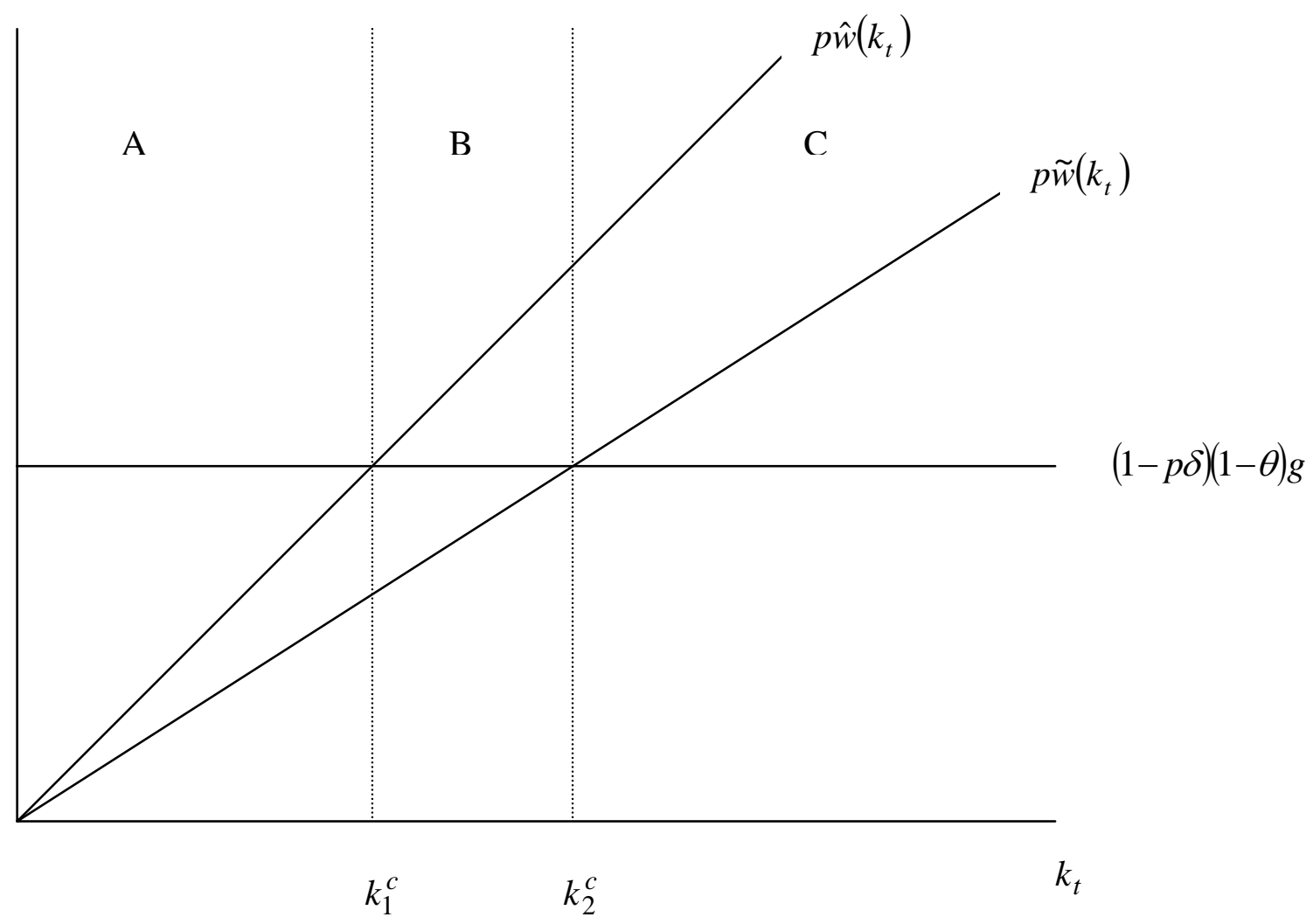

Fig 2: Corruption and Development 
Proposition 1 For $k_{t}<k_{1}^{c}$, there exists a unique equilibrium in which all corruptible bureaucrats are corrupt.

Proof. Suppose that $k_{t}<k_{1}^{c}$ (Region A in Figure 2). Then $p \hat{w}\left(k_{t}\right)<(1-p \delta)(1-\theta) g$ and $p \tilde{w}\left(k_{t}\right)<(1-p \delta)(1-\theta) g$, implying that it pays each corruptible bureaucrat to be corrupt, irrespective of whether other corruptible bureaucrats are corrupt or non-corrupt. The case in which all such bureaucrats are corrupt is an equilibrium outcome since none of them has an incentive to deviate from corrupt behaviour. Conversely, the case in which all such bureaucrats are non-corrupt is not an equilibrium outcome since each of them has an incentive to deviate from non-corrupt behaviour.

\section{Proposition 2 For $k_{t}>k_{1}^{c}$, there exists a unique equilibrium in which no corruptible bureaucrat is corrupt.}

Proof. Suppose that $k_{t}>k_{1}^{c}$ (Region $C$ in Figure 2). Then $p \hat{w}\left(k_{t}\right)>(1-p \delta)(1-\theta) g$ and $p \widetilde{w}\left(k_{t}\right)>(1-p \delta)(1-\theta) g$, implying that it pays each corruptible bureaucrat to be non-corrupt, irrespective of whether other corruptible bureaucrats are corrupt or non-corrupt. The case in which all such bureaucrats are non-corrupt is an equilibrium outcome since none of them has an incentive to deviate from non-corrupt behaviour. Conversely, the case in which all such bureaucrats are corrupt is not an equilibrium outcome since each of them has an incentive to deviate from corrupt behaviour.

Proposition 3 For $k_{t} \in\left(k_{1}^{c}, k_{2}^{c}\right)$, there are multiple equilibria in which all corruptible bureaucrats are either corrupt or non-corrupt.

Proof. Suppose that $k_{t} \in\left(k_{1}^{c}, k_{2}^{c}\right)$ (Region B in Figure 2). Then $p \hat{w}\left(k_{t}\right)>(1-p \delta)(1-\theta) g$ but $p \tilde{w}\left(k_{t}\right)<(1-p \delta)(1-\theta) g$, implying that it pays each corruptible bureaucrat to be either corrupt or non-corrupt, depending on whether other corruptible bureaucrats are corrupt or non-corrupt. The case in which all such bureaucrats are corrupt is an equilibrium outcome since none of them has an incentive to deviate from corrupt behaviour. Likewise, the case in which all such bureaucrats are noncorrupt is also an equilibrium outcome since none of them has an incentive to deviate from noncorrupt behaviour.

This result demonstrates that intermediate levels of development may be associated with either low or high levels of corruption.

The main implication of the foregoing analysis is that an economy may find itself in either of three distinct types of development regime where corruption and development is generally negatively correlated and two-way causal: the first, a low development regime, is characterised by a unique equilibrium associated with a high incidence of corruption and public spending (investment) with lower quality (productivity); the second, a high development regime, is also characterised by a unique equilibrium but one that entails a low incidence of corruption and public investment with higher quality 
(productivity); the third, an intermediate development regime, is characterised by multiple equilibria with varying incidences of corruption.

The existence of multiple equilibria means that countries may display different levels of corruption at similar stages of development. Consequently, and in accordance with the empirical evidence, our analysis is able to explain not only why there is more corruption in poor countries than in rich countries, but also why there is more diversity in corruption among middle-income countries. It is also able to account for persistence in both corruption and income inequalities across countries: transition from a low development (high corruption) regime to a high development (low corruption) regime is not inevitable in our model, and it is possible for an economy to remain trapped in the former unless fundamental changes take place.

In fact the results obtained above do not exhaust the full set of outcomes that are possible at intermediate stages of development. Until now, we have confined our attention to the two pure strategy equilibria - that is, equilibria in which all corruptible bureaucrats behave in exactly the same way. Yet there is also a mixed strategy equilibrium in the intermediate stage of development - that is, an equilibrium in which bureaucratic behaviour is heterogeneous. More precisely, this equilibrium entails a fraction, $\mu \in(0,1)$, of corruptible bureaucrats who are corrupt, while the remaining fraction, $1-\mu$, are not corrupt. We show in Section 5.2 by establishing that for each $k_{t} \in\left(k_{1}^{c}, k_{2}^{c}\right)$, there exists a $\mu$ such that the incentive condition in (3) holds with equality. This means that a middle-income country could find itself in any one of these possible equilibria with an incidence of corruption that is high, low or somewhere in between.

\section{Corruption and Thresholds of Development: A Comparative Static Analysis}

We have seen how the incidence of corruption depends on the level of development, where development (in terms of capital accumulation or output per capita) stages have a negative correlation for low and high development regimes while the relation is weak (or ambiguous) in the intermediate development regime. We find two clear thresholds $k_{1}^{c}$ and $k_{2}^{c}$ where for $k_{t}<k_{1}^{c}$, the economy is corrupt and for $k_{t}>k_{2}^{c}$, the economy is non-corrupt but for $k_{t} \in\left(k_{1}^{c}, k_{2}^{c}\right)$, the incidence of corruption depends on the already existing culture of corruption.

\subsection{Thresholds and Culture}

As mentioned earlier, according to (6) and (7), there are three possible parameters within our analysis, i.e., $p$ (probability of detection) ${ }^{15}, \theta$ (quality or productivity of public service) and $\delta$ (the illegal resource that a bureaucrat finds difficult to hide), that can affect the thresholds alongside economic 
development. It is notable that these parameters could be increasing functions of monitoring expenditures by the government, improvement in the rule of law and improved information flows, all of which reflect better culture in the economy. From (6) and (7), we find that both $k_{1}^{c}$ and $k_{2}^{c}$ depend on $p, \theta$ and $\delta$.

Proposition 4 Increase in the risk of being corrupt (p), increase in the productivity of public services $(\theta)$, and increase in the difficulty of hiding illegal earnings $(\delta)$ may lead to decline in both thresholds, which eventually may lead to the collapse of the intermediate regime (i.e., $\left.k_{2}^{c}-k_{1}^{c} \rightarrow 0\right)$ asymptotically. But as $p, \theta$ and $\delta \in(0,1)$, thresholds would remain, i.e., there would be some countries that would fall into poverty traps.

Proof. Differentiating (6) and (7) and their gap with respect to $p, \theta$ and $\delta$, we get respectively,

For $p$ :

$$
\frac{\partial k_{1}^{c}}{\partial p}=-\frac{\Lambda(1-\theta)}{p^{2}}<0 ; \frac{\partial k_{2}^{c}}{\partial p}=-\frac{\Lambda(1-\theta)}{p^{2} \theta^{\beta}}<0 ; \frac{\partial\left(k_{2}^{c}-k_{1}^{c}\right)}{\partial p}=-\frac{\Lambda(1-\theta)\left(1-\theta^{\beta}\right)}{p^{2} \theta^{\beta}}<0 ;
$$

For $\theta$.

$$
\begin{aligned}
& \frac{\partial k_{1}^{c}}{\partial \theta}=-\frac{\Lambda(1-p \delta)}{p}<0 ; \frac{\partial k_{2}^{c}}{\partial p}=-\frac{\Lambda(1-p \delta)[\theta+\beta(1-\theta)]}{p \theta^{(1+\beta)}}<0 ; \\
& \frac{\partial\left(k_{2}^{c}-k_{1}^{c}\right)}{\partial p}=-\frac{\Lambda(1-p \delta)\left[\theta\left(1-\theta^{\beta}\right)+\beta(1-\theta)\right]}{p \theta^{(1+\beta)}}<0 ;
\end{aligned}
$$

For $\delta$.

$$
\frac{\partial k_{1}^{c}}{\partial \delta}=-\Lambda(1-\theta)<0 ; \frac{\partial k_{2}^{c}}{\partial \delta}=-\frac{\Lambda(1-\theta)}{\theta^{\beta}}<0 ; \text { and } \frac{\partial\left(k_{2}^{c}-k_{1}^{c}\right)}{\partial \delta}=-\frac{\Lambda(1-\theta)\left(1-\theta^{\beta}\right)}{\theta^{\beta}}<0
$$

\subsection{Thresholds and Culture of Corruption}

The diversity of outcomes at intermediate levels of development is greater than what we have suggested so far. Each of the equilibria that has been considered is a pure strategy equilibrium in which all bureaucrats are either corrupt or non-corrupt. But there also exists a mixed strategy equilibrium in which a fraction, $\mu \in(0,1)$, of bureaucrats are corrupt, while the remaining fraction, $1-\mu$, are noncorrupt for $k_{t} \in\left(k_{1}^{c}, k_{2}^{c}\right)$. In this case, each of the $1-\mu(\mu)$ fraction of bureaucrats would provide the firms with $g(\theta g)$ units of productive public services. The economy would acquire total productive public services $\bar{G}=[1-\mu(1-\theta)] n g$. Under such circumstances, wage rate in (2) is $\bar{w}\left(k_{t}\right)=\alpha A l^{\alpha-1}[1-\mu(1-\theta)]^{\beta}(n g)^{\beta} k_{t}$ and the incentive condition in (3) becomes

$$
(1-p \delta)(1-\theta) g \geq p \bar{w}\left(k_{t}\right)
$$

\footnotetext{
15 The risk of being corrupt (i.e., $p$ ) has been treated as a function of culture of corruption in Andvig and Moene (1990) and Mauro (2004), among others.
} 
It is straightforward to verify that, for a given $k_{t}$ and a given $\mu \in(0,1), \tilde{G}<\bar{G}<\hat{G}$ and $\widetilde{w}\left(k_{t}\right)<\bar{w}\left(k_{t}\right)<\hat{w}\left(k_{t}\right)$, while the left hand side of the incentive condition of (8) is the same as in (4) and (5). It is also straightforward to verify that $\bar{G}=\hat{G}$ and $\bar{w}()=.\hat{w}($.$) if \mu=0$, while $\bar{G}=\tilde{G}$ and $\bar{w}(\cdot)=\tilde{w}(\cdot)$ if $\mu=1$. Finally, we note that the slope of $\bar{w}(\cdot)$ is declining in $\mu$. In terms of Figure 2, these properties imply that, for any given $\mu \in(0,1)$, the wage line $\bar{w}(\cdot)$ always lies between the lines $\hat{w}(\cdot)$ and $\tilde{w}(\cdot)$, while the left hand side of $(8)$ is constant. It follows that within the region $k_{t} \in\left(k_{1}^{c}, k_{2}^{c}\right)$, there exists a $\mu \in(0,1)$, such that $p \bar{w}(\cdot)=(1-p \delta)(1-\theta) g$, implying that each bureaucrat is indifferent between being corrupt or non-corrupt. This $\mu$ is the fraction of corrupt bureaucrats that supports a mixed strategy equilibrium, which depends on how many people are corrupt (non-corrupt) in the economy.

Considering $\mu$ (fraction of corrupt bureaucrats) as the culture of corruption, we find a new critical level, $k_{\mu}^{c}$. Substituting values for $\bar{w}\left(k_{t}\right)$ in (8) we may identify $k_{\mu}^{c}$ as

$$
k_{\mu}^{c}=\Lambda\left[\frac{(1-p \delta)(1-\theta)}{p[1-\mu(1-\theta)]^{\beta}}\right]
$$

Proposition 5 The intermediate levels of development may collapse into either low development with povertycorruption trap (where $\mu=1$ ) or high development -low corruption regime (where $\mu=0$ ) depending on the existing culture of corruption $(\mu)$

Proof: It is easy to verify that $k_{\mu}^{c}$ is declining in $\mu$ and it collapses to either $k_{1}^{c}$ or $k_{2}^{c}$, depending on whether $\mu=0$ or $\mu=1$ respectively. This result demonstrates that the intermediate levels of development may collapse into either low development with poverty-corruption trap (where $\mu=1$ ) or a high development - low corruption regime (where $\mu=0$ ) depending on the existing culture of corruption $(\mu)$.

\section{Section 6: Data Sample and Characteristics}

Since the early 1980s, a number of organisations - most notably, Business International Corporation, Political Risk Services Incorporated and Transparency International - have published various cross-country data sets on measures of corruption, derived from survey questionnaires sent to networks of correspondents around the world. These corruption indices rank countries according to the extent to which corruption in public (and political) office is perceived to exist. While differing in their precise construction, the indices are very closely correlated with each other, lending support to the 
contention that they provide reliable estimates of the actual extent of corruption activity ${ }^{16}$. The data used in this study are from Transparency International and are available for various time periods from 1980 to 2003.

In order to maximise the number of observations and to control for any business cycle effects in our GDP per capita data we arrange the data into five non-overlapping time periods. These are 1980-1985, 1988-1992, 1995-1997, 1998-2000, and 2001-2003. There are missing years in this sequence as a result of the unavailability of the corruption index for all years. GDP is measured as GDP per capita and is taken from the WDI CDROM 2002. Table 1 reports some summary statistics of corruption and GDP.

Table 1: Summary Statistics

\begin{tabular}{|c|c|c|c|}
\hline Time Period & Observations & Corruption & Ln(GDPp $_{t-1}$ \\
\hline $1980-1985$ & 50 & 4.58 & 8.31 \\
& & $(2.72)$ & $(1.56)$ \\
\hline $1988-1992$ & 51 & 4.72 & 8.37 \\
& & $(2.79)$ & $(1.59)$ \\
\hline $1995-1997$ & 57 & 4.75 & 8.42 \\
& & $(2.56)$ & $(1.58)$ \\
\hline $1998-2000$ & 90 & 5.34 & 8.01 \\
& & $(2.40)$ & $(1.58)$ \\
\hline $2001-2003$ & 90 & 5.35 & 8.07 \\
& & $(2.41)$ & $(1.59)$ \\
\hline $1980-2003$ & 338 & 5.04 & 8.19 \\
& & $(2.55)$ & $(1.58)$ \\
\hline
\end{tabular}

The mean value of corruption across all countries and time periods is just over 5 . The least corrupt country is Denmark, with a corruption score of 0.07 (1998-2000), and the most corrupt country is Bangladesh, with the maximum score of 10 (1988-1992). There would appear to be two broad groups of countries however, those with a corruption score below three and those with medium to high corruption (a corruption score between $5 / 6$ and 8/9). Countries with low corruption are typically those from OECD countries, whereas there is a greater mix amongst those with high corruption. For example, the countries with a corruption score between 7 and 8 include countries from Latin America, Eastern \& Central Europe, Asia and Africa. Overall the correlation between corruption and (the lag of the $\log$ ) of GDP per capita is -0.85 . This negative correlation is indicative of similar results using more formal regression analysis in the empirical literature.

${ }^{16}$ For more detailed discussions, see Ades and Di Tella (1997), Jain (1998), Tanzi and Davoodi (1997) and Treisman (2000). 
We also find evidence of the second stylised fact in our data: in general there is little time variation in the corruption score for many countries. The correlation between the corruption index between the earliest time period in the sample (1980-1985) and the latest time period (2001-2003) is 0.87. Of the 54 countries with data over the full sample period the corruption index decreased (lower corruption) in 33 countries and increased (higher corruption) in 21. Generally these cross-time changes were small. Of these 21 countries, 11 saw a worsening greater than 1 point on the corruption index and just five greater than 2 points. These latter five countries were Argentina, Cameroon, Ecuador, Russia and South Africa. Of the 33 countries improving on their 1980-85 score, 12 improved by more than one point on the index and just 2 countries by more than 2 points (Egypt and Hungary).

\section{Section 7: Formal Threshold Model}

The model developed in this paper predicts that the correlation between corruption and development will vary with the level of development. Specifically, there are break-points around which the relationship between corruption and development changes which can be influenced by the already existing culture (of corruption) in the economy. We assume that the location of these break points, or thresholds, can be identified using information from the slope parameters in a regression of corruption and development. The testing procedure used to locate the position and significance of any thresholds in the GDP/corruption relationship is the same as that used by Girma et al (2003) and Papageorgiou (2002). To understand the problems associated with the application of the testing procedure assume for simplicity that the corruption-GDP relationship is captured by the single threshold equation given below:

$$
C O R R_{i t}=\gamma X_{i t}+\beta_{1} \log (G D P)_{i t} I\left(G D P_{i t} \leq \alpha\right)+\beta_{2} \log (G D P)_{i t} I\left(G D P_{i t}>\alpha\right)+\varepsilon_{i t}
$$

where CORR is corruption, I(.) is an indicator function and $\beta$ and $\gamma$ are parameters to be estimated. Evidence of a threshold in the effect of GDP on corruption would be associated with a difference in the effect of GDP on corruption above and below the critical value of GDP, $\beta_{1} \neq \beta_{2}$, where $\alpha$ identifies the break-point value of GDP. In estimation there are three steps: firstly, jointly estimate the threshold value $\alpha$ and the slope coefficients $\gamma, \beta_{1}$, and $\beta_{2}$. Secondly, test the null of no threshold (i.e. $H_{0}: \beta_{1}=\beta_{2}$ ) against the alternative hypothesis of a threshold model (i.e. $\beta_{1} \neq \beta_{2}$ ) and thirdly, construct confidence intervals for $\alpha$.

To estimate the parameters of the equation we use the algorithm provided in Hansen (2000), which searches over values of $\alpha$ sequentially until the sample splitting value $\hat{\alpha}$ is found ${ }^{17}$. Once found, estimates of $\gamma, \beta_{1}$ and $\beta_{2}$ are readily provided. The problem that arises in testing the null hypothesis of no threshold effect (i.e. a linear formulation) against the alternative of a threshold effect

\footnotetext{
${ }^{17}$ This is the value of $\alpha$ that minimises the concentrated sum of squared errors based on a conditional OLS regression.
} 
is that, under the null hypothesis, the threshold variable is not identified. Consequently, classical tests such as the Lagrange Multiplier (LM) test do not have standard distributions and so critical values cannot be read off standard distribution tables. To deal with this problem, Hansen (2000) recommends a bootstrap procedure to obtain approximate critical values of the test statistics, which allows one to perform the hypothesis test. We follow Hansen (2000) and bootstrap the p-value based on a likelihood ratio $(\mathrm{LR})$ test.

If a threshold effect is found (i.e. $\beta_{1} \neq \beta_{2}$ ), then a confidence interval for the critical level of GDP per capita is generated. In this case one needs to test for the particular threshold value as: $H_{o}: \alpha=\alpha_{0}$. We require this confidence interval to be reasonably small, given countries within it cannot be confidently placed in either regime.

It should be noted that the test of the null hypothesis for forming the confidence interval is not the same as that for the second problem i.e. the test of no threshold effect. Under normality, the likelihood ratio test statistic $\operatorname{LR}_{n}(\alpha)=n \frac{S_{n}(\alpha)-S_{n}(\hat{\alpha})}{S_{n}(\hat{\alpha})}$ is commonly used to test for particular parametric values. However, Hansen (2000) proves that when the endogenous sample-splitting procedure is employed, $\operatorname{LR}_{n}(\alpha)$ does not have a standard $\chi^{2}$ distribution. Consequently, he then derives the correct distribution function and provides a table of the appropriate asymptotic critical values and search over the remainder of the sample. ${ }^{18}$

Having identified the location of the first threshold the process is then repeated to find further thresholds. To do this we follow Papageorgiou (2002) and split the sample at the point of the first threshold value.

\section{Section 8: Thresholds in Corruption}

In this section of the paper we test more formally for the negative correlation between corruption and GDP in Figure 1 and for thresholds in this relationship. To begin however, we report in Table 1 the results from a regression of corruption against the lag of the log of GDP per capita as a basis for comparison. A couple of points are worth noting about this regression. Firstly, we do not include other control variables suggested by the literature, choosing instead to explore the effect of adding additional control variables further below. Secondly, the theoretical model developed predicts a two-way causal relationship between corruption and development. Corruption both causes and is caused by development levels. For this reason, and given our interest in the location of thresholds, we do not attempt to deal with the issue of endogeneity in our regressions, choosing instead to leave establishing whether they are caused by the effect of development on corruption or the reverse to future work. However, in order to maximise the data points available to us (the GDP per capita data

\footnotetext{
18 See Table I on page 582 of Hansen (2000).
} 
end in 2000 and the corruption data in 2003) we remain consistent with the existing empirical literature and use the lag of GDP per capita rather than its contemporaneous value. Whilst we do not interpret it as such here, this approach is often used to minimise the effect of endogeneity on the results.

Table 2: Corruption and GDP

\begin{tabular}{|c|c|c|c|c|c|c|c|}
\hline $\begin{array}{c}\text { Regression } \\
\text { No. }\end{array}$ & 1 & 2 & 3 & 4 & 5 & 6 & 7 \\
\hline Description & base & $1980-85$ & $1988-92$ & $1995-97$ & $1998-2000$ & $2001-03$ & thresholds \\
\hline $\log (\mathrm{GDP})_{\mathrm{t}-1}$ & -1.371 & -1.400 & -1.501 & -1.388 & -1.286 & -1.334 & -1.068 \\
$(28.20)^{* *}$ & $(8.23)^{* *}$ & $(10.21)^{* *}$ & $(13.95)^{* *}$ & $(13.22)^{* *}$ & $(16.56)^{* *}$ & $(14.31)^{* *}$ \\
\hline $0.04<\mathrm{I}$ & & & & & & & -0.410 \\
$\log (\mathrm{GDP})_{\mathrm{t}-1}$ & & & & & & & $(5.44)^{* *}$ \\
\hline $\mathrm{I}>0.75$ & & & & & & & \\
$\log (\mathrm{GDP})_{\mathrm{t}-1}$ & & & & & & & \\
\hline Constant & 16.270 & 16.225 & 17.286 & 16.438 & 15.645 & 16.117 & 14.342 \\
& $(40.10)^{* *}$ & $(10.53)^{* *}$ & $(13.20)^{* *}$ & $(20.48)^{* *}$ & $(20.53)^{* *}$ & $(25.49)^{* *}$ & $(26.69)^{* *}$ \\
\hline Obs. & 338 & 50 & 51 & 57 & 90 & 90 & 338 \\
\hline R-squared & 0.72 & 0.64 & 0.73 & 0.73 & 0.72 & 0.77 & 0.78 \\
\hline
\end{tabular}

In accordance with the theoretical model and existing empirical research there is a strong negative well-identified correlation between the level of GDP and corruption. Increasing levels of development are associated with lower levels of corruption. Also, as expected, we are able to explain a large proportion of the variation of corruption across countries using just this variable. The adjusted $\mathrm{R}^{2}$ is over 70 per cent. The coefficient suggests that an increase in the log of GDP by one standard deviation (1.59) is associated with a reduction in the level of corruption equal to 2.2 points on the corruption index. One standard deviation of the corruption index is according to Table 12.55 .

This correlation between corruption and GDP is independent of the time period used. In regressions 2 to 6 we re-estimate the regression for each time period separately. As can be seen from the Table 2 despite the increase in the number of observations towards the end of the time period the coefficient on GDP remains similar, varying between -1.5 (1988-1992) and -1.3 (1998-2000).

Searching for a threshold in regression 1 we find evidence of a significant break in the value of the coefficient on the log of GDP at the $75^{\text {th }}$ percentile. This corresponds to a GDP value of $\$ 12,700$ (the GDP per capita of Hong Kong between 1980 and 1985) with a bootstrapped p-value ${ }^{19}$ of 0.00 . Denoting the percentiles of the log of GDP by $\alpha$, the $95 \%$ confidence interval for the threshold estimates is obtained by plotting the likelihood ratio sequence in $\alpha, \operatorname{LR}(\alpha)$, against $\alpha$ and drawing a flat line at the critical value (e.g. the $95 \%$ critical value is 7.35 ). The segment of the curve that lies below 
the flat line will be the confidence interval of the threshold estimate. Figure 3 below illustrates how the $95 \%$ confidence interval for the first threshold is $\mathrm{GDP}_{\mathrm{t}-1} \in[\$ 11,300, \$ 13,900]$ or in terms of percentiles [p (73), p (76)]. The threshold would therefore appear to be well identified within the data.

\section{Figure 3:}

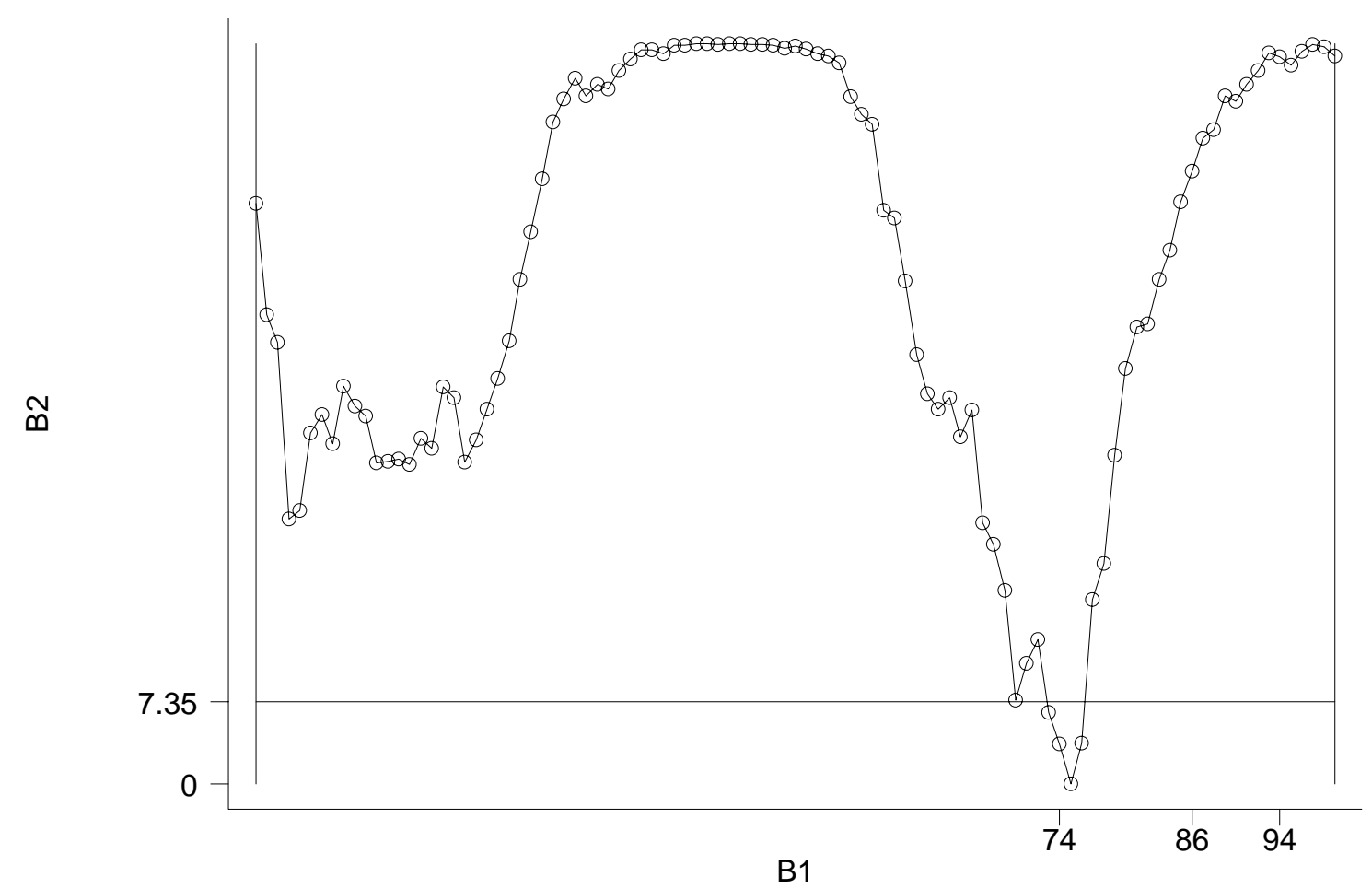

In Table 3 below we report the country (and time period) that lie in the 5 percentiles up to and above the first threshold. Countries above and below the threshold values are denoted in white cells, countries within the uncertainty region are denoted in light grey and those at the threshold point are in dark grey cells. Four countries lie on the threshold point, Hong Kong, UK, Italy, Israel while there are 12 observations within the confidence interval, including observations from Greece, Ireland, Spain, Portugal, Israel, South Korea, Singapore, UK, New Zealand, Italy and Hong Kong.

A noticeable result from this table is the drop in the level of corruption between the two groups. The corruption scores of those countries just to the right of the threshold are generally lower than those just to the left of this point. The exceptions to this rule are the five countries that transit between this first threshold (and out of the uncertainty range) over the time period. These countries are Israel, Ireland, Singapore, Spain and Hong Kong. These five countries are all a-typical of the rest of the countries in the middle regime in that they all have corruption scores that are much closer to those above the upper threshold. The average level of corruption in the middle range is 6.9 whereas corruption in the last period before they switch regimes in the five countries ranges from 1.6 (Singapore) to 3.4 (Spain). These corruption levels are close to the average level of corruption in the

${ }^{19}$ All of the bootstrapped p-values in our endogenous threshold analysis are generated using 1000 bootstrap replications. 
upper threshold at 2.1. Interestingly the cross-time pattern is very similar for these five countries. In the first time period (1980-1985) they all lay below the upper threshold value. In the period 1988-1992 all except Spain lie within the uncertainty region (Spain is below) and in the next period 1995-1997 (the fourth time period in the case of Israel \& Spain) they lie above the uncertainty region.

Table 3:

\begin{tabular}{|c|c|c|c|c|c|c|c|}
\hline $\begin{array}{l}\text { Percentile } \\
\text { Of GDP }\end{array}$ & Country & $\begin{array}{c}\text { Corruptn. } \\
\text { Score }\end{array}$ & $\begin{array}{l}\text { Time } \\
\text { Period }\end{array}$ & $\begin{array}{l}\text { Percentile } \\
\text { Of GDP }\end{array}$ & Country & $\begin{array}{c}\text { Corruptn. } \\
\text { Score }\end{array}$ & $\begin{array}{l}\text { Time } \\
\text { Period }\end{array}$ \\
\hline 69 & S. Korea & 5.47 & 3 & 74 & Singapore & 0.84 & 2 \\
\hline 69 & Argentina & 7.07 & 5 & 74 & Portugal & 3.60 & 5 \\
\hline 70 & Singapore & 1.59 & 1 & 74 & Greece & 5.77 & 5 \\
\hline 70 & Hong Kong & 2.65 & 1 & 75 & Hong Kong & 3.13 & 2 \\
\hline 70 & Slovenia & 4.25 & 4 & 75 & Italy & 5.14 & 1 \\
\hline 70 & Portugal & 3.65 & 3 & 75 & UK & 1.99 & 1 \\
\hline 71 & Ireland & 1.72 & 1 & 75 & Israel & 2.13 & 3 \\
\hline 71 & Greece & 5.80 & 1 & 76 & Spain & 5.15 & 3 \\
\hline 71 & Greece & 4.95 & 2 & 76 & New Zealand & 1.59 & 1 \\
\hline 71 & Israel & 2.73 & 1 & 76 & Ireland & 1.57 & 3 \\
\hline 71 & Spain & 3.18 & 1 & 76 & UK & 1.74 & 2 \\
\hline 72 & Greece & 5.20 & 3 & 76 & New Zealand & 0.70 & 2 \\
\hline 72 & Spain & 4.94 & 2 & 77 & New Zealand & 0.60 & 3 \\
\hline 72 & Slovenia & 4.30 & 5 & 77 & Italy & 5.70 & 2 \\
\hline 72 & Portugal & 3.47 & 4 & 77 & Australia & 1.59 & 1 \\
\hline 73 & Ireland & 2.32 & 2 & 77 & Spain & 3.43 & 4 \\
\hline 73 & S. Korea & 6.00 & 4 & 78 & Canada & 1.59 & 1 \\
\hline 73 & Greece & 5.10 & 4 & 78 & Israel & 3.17 & 4 \\
\hline 73 & Israel & 2.56 & 2 & 78 & Australia & 1.80 & 2 \\
\hline 74 & S. Korea & 5.67 & 5 & 78 & New Zealand & 0.60 & 4 \\
\hline
\end{tabular}

Note: Time period 1= 1980-85; 2 = 1988-92; 3 = 1995-97; 4 = 1998-2000; 5 = 2001-03.

Another result of interest from Table 3, although not perhaps evident at first, is the change in the corruption scores for those countries that lie just above and just below the threshold. For countries that are approaching the threshold from below but do not cross the threshold point during the period, the change in the corruption index is not clearly downwards. So for example, of 11 countries that have a GDPpc that lies less than 10 percentage points below the threshold (i.e. between the $65^{\text {th }}$ and $75^{\text {th }}$ percentiles of GDPpc) the corruption index increases in 5 and decreases in 6 . There are no patterns in 
corruption across time. In contrast, for all countries that lay just above the threshold and moved away from this point over time the corruption index fell. Of the 5 countries that lie less than 10 percentage points above the threshold point (i.e. between $75^{\text {th }}$ and $85^{\text {th }}$ percentiles of GDPpc) the corruption index fell in all of them. Amongst these five countries is Italy, which in period 1 lay within the uncertainty region and whose corruption levels fell from 5.14 in 1980-85 to 4.7 by 2001-03. Of the five countries that transited between thresholds over the sample period corruption fell in four and increased in one (Hong Kong), albeit from a low level. Is summary, then there would be distinct differences in corruption both between countries and within countries according to their location above or below the threshold point.

A second significant threshold is identified at the $4^{\text {th }}$ percentile (equal to a GDP value of \$215). Again this threshold is significant with a 95 per cent confidence interval that is small in size [p (4), p (8)]. Again in Table 4 we report the countries in and around this threshold point. The countries below this bottom threshold point are Malawi, Tanzania, Mozambique, Vietnam and China. There are 13 observations for which we are uncertain whether they lie in the lower or middle regime. These include observations from Uganda, Nigeria, Kenya, Bangladesh, India and Vietnam. Two observations stand out from Table 4: firstly, outside of perhaps China, none of the low-income countries included have low corruption scores. Secondly, unlike for the first identified threshold in Table 3 there does not appear to be a large difference in the corruption scores for countries either side of the identified threshold. The average corruption score of the countries up to an including the threshold point is 7.1, whereas for those in the middle range it is 6.9.

Once again there appears to be very few countries that transit between the identified thresholds (and out of the uncertainty region). China is below the threshold in 1988-1992 and then above the threshold in 1995-1997, while Vietnam is below the threshold in 1995-1997, in the uncertainty region in 1998-2000 and above the threshold in the final time period. Once again we also find that these countries have corruption levels that are close to or below the average from the group that they are leaving. The average level of corruption in the lower group is 7.0 while corruption in China was 4.9 and Vietnam 7.2. In summary, for this threshold the distinction between countries above and below the threshold point and over time would therefore appear less distinct than the first identified threshold.

Evidence is also found for a third threshold $\left[\$ 626,18^{\text {th }}\right.$ percentile]. However the exact location of this threshold is difficult to place and the confidence interval extends from the $4^{\text {th }}$ to the $75^{\text {th }}$ percentiles i.e. from the lower to the upper thresholds. For this reason we concentrate on the two well identified thresholds in our data. 
Table 4:

\begin{tabular}{|cccc|cccc}
\hline $\begin{array}{c}\text { Percentile } \\
\text { of GDP }\end{array}$ & Country & $\begin{array}{c}\text { Corruptn. } \\
\text { Score }\end{array}$ & $\begin{array}{c}\text { Time } \\
\text { Period }\end{array}$ & $\begin{array}{c}\text { Percentile } \\
\text { of GDP }\end{array}$ & Country & $\begin{array}{c}\text { Corruptn. } \\
\text { Score }\end{array}$ & $\begin{array}{c}\text { Time } \\
\text { Period }\end{array}$ \\
\hline 0 & China & 4.87 & 1 & 5 & Nigeria & 8.95 & 3 \\
1 & Mozambique & 7.15 & 4 & 6 & Nigeria & 8.43 & 4 \\
1 & Malawi & 5.90 & 4 & 6 & Bangladesh & 8.34 & 3 \\
2 & Malawi & 7.03 & 5 & 6 & Pakistan & 8.48 & 1 \\
2 & Tanzania & 7.90 & 4 & 6 & Vietnam & 7.47 & 4 \\
3 & Tanzania & 7.53 & 5 & 7 & Nigeria & 9.01 & 1 \\
3 & Mozambique & 7.30 & 5 & 7 & Kenya & 6.73 & 1 \\
3 & China & 5.27 & 2 & 7 & Uganda & 7.63 & 4 \\
3 & Vietnam & 7.21 & 3 & 7 & India & 7.28 & 3 \\
4 & Bangladesh & 9.22 & 1 & 8 & Bangladesh & 9.60 & 4 \\
4 & India & 6.33 & 1 & 8 & Kenya & 8.40 & 2 \\
4 & Uganda & 6.73 & 2 & 8 & Kenya & 8.07 & 5 \\
4 & India & 7.11 & 2 & 8 & Uganda & 7.93 & 5 \\
4 & Bangladesh & 10.00 & 2 & 9 & Kenya & 7.80 & 4 \\
5 & Uganda & 7.33 & 3 & 9 & Vietnam & 7.53 & 5 \\
5 & Nigeria & 8.67 & 5 & 10 & Kenya & 7.69 & 3 \\
5 & Nigeria & 9.37 & 2 & & & & \\
\hline
\end{tabular}

In the final regression of Table 1 we allow the coefficient on the level of development to vary across the three regions. The coefficients are organised such that they test for differences in the estimated relationship between GDP per capita and corruption relative to the middle regime (between percentiles 4 to 75). Comparing to regression 1, an unsurprising outcome from this exercise is that the fit of the regression improves, the adjusted $\mathrm{R}^{2}$ increases from 72 to 78 percent. The results from this regression suggest that relative to the middle range of GDP per capita values the effect of GDP per capita on corruption is stronger in the upper and lower regimes, significantly so in both cases. This is perhaps also unsurprising given the greater variability of corruption scores for countries within the middle range of income values. It is also interesting to note however that relative to the slope parameter estimated under the model with no thresholds (regression 1) the coefficient is lower in absolute value for the middle and upper portions of the sample. Moreover we can reject the hypothesis that the slope parameter is equal to that found in regression $1(-1.371)$ at the 1 per cent level of significance for both of these clubs. Not accounting for the possibility of thresholds in the relationship between corruption and development has the effect of biasing upwards the strength of the estimated relationship. 
We test the robustness of these findings to the use of particular time periods. Restricting the samples to either the period from 1998 to 2000, or from 2001 to 2003 does not change the results. Over the first time period evidence of two significant thresholds is again found, located at the $75^{\text {th }}$ and $3^{\text {rd }} / 4^{\text {th }}$ percentiles, while over the latter period they are found to be located at the $75^{\text {th }}$ and $5^{\text {th }}$ percentiles. The results are robust to the use of cross-section data.

\subsection{Culture and Openness}

In this section we consider whether the addition of measures of culture (socio-economic and institutional) and openness to international trade help to explain the location of the threshold relationship between corruption and GDP per capita. Our model suggests that (i) countries can get stuck in high or low corruption equilibria (as in Mauro, 2004), which we label as corruption clubs; (ii) that which equilibria a country would fall into depends on its level of development; and (iii) (bureaucratic) culture seems to play a role in defining the equilibrium relationship between corruption and development only in the middle development regime. In our comparative static analysis in Section 5 , we have shown that probability of detection $(p)$, quality or productivity of public service $(\theta)$, the illegal resource that a bureaucrat finds difficult to hide $(\delta)$ and fraction of corrupt bureaucrats $(\mu)$ can affect the thresholds alongside economic development. It is notable that these parameters could be increasing functions of monitoring expenditures by the government, improvement in the rule of law, better information flows that can be achieved through better political institutions (e.g., democracy) and higher political stability, all of which reflect better culture in the economy. We want to explore this issue in our empirical analysis by including several cultural variables that are widely used in the literature.

Alternatively, in order to see the role played by variables other than culture, we also use measures of openness to international trade. A number of studies have suggested a correlation between corruption and openness. Ades and Di Tella (1997, 1999) for example argue that greater openness brings greater competition to the economy which reduces corruption, whereas Wei (2000) suggests that open countries experience greater losses from corruption than less open ones because corruption creates distortions on foreign transactions. In a thought provoking survey, Winters (2004) suggests that trade policy can contribute positively to the fight against corruption. Fisman (2000) argues for tariff uniformity and shows that corruption is positively correlated with the variance of tariff rates across countries.

\section{Culture}

We measure various aspects of a country's culture including its democratic status, colonial heritage, religion and political stability. The first two measures are intended to capture institutional elements of culture, namely whether the country has been democratic in all years between 1950 and 1995 and colonial heritage. It is the legal framework of British colonial heritage which has been seen to 
drive the importance of this variable in previous work, with the establishment of a strict set of rules seen as particularly important in this regard (Triesman, 2000). In turn, democratic status is believed to be correlated with the probability of being caught as corrupt, being associated therefore with lower levels of corruption. Both of these variables have been shown to be significantly correlated with corruption by Treisman (2000). The data for these variables are from Treisman (2000) and measured as zero one variables.

Treisman (2000) also suggests that corruption is significantly correlated with the extent of Protestant religion in society, where "religious traditions have often been thought to condition cultural attitudes towards social hierarchy" (Treisman, 2000 p 6) the reason given for its correlation with corruption. Here we use the percentage of the population that belong to a Protestant religion from the U.S. Bureau of the Census International Data Base. Unfortunately the available time series on each country in this dataset differs markedly. Owing to this difficulty in constructing a common time series and given we might expect that the between country variation is more important than the within country variation we take the value for 1981 as a representative year. The results for this variable are robust to the use of data for 2001 as an alternative, where the correlation between the values for 1981 and 2001 are also very high at 94.6 per cent. ${ }^{20}$

Corruption is also commonly regressed against measures of political instability. Unfortunately the commonly used source for this data set (World Bank) ends well before the sample period used here. As an alternative we use information from the Armed Conflict Dataset by Strand, Wilhelmsen \& Gleditsch (2003). This source classifies conflict according to the territory on which it is fought, provides the time period over which the conflict took place and grades the intensity of the conflict. From the dataset we use information on the intensity of the conflict for all conflicts internal to the country. This is the first time that this variable has been used in the literature.

Table 5: Cultural Variables and Corruption.

\begin{tabular}{|c|c|c|c|c|c|}
\hline Variable & Observations & Mean & Std. Dev & Min & Max \\
\hline Democracy & 546 & 0.219 & 0.414 & 0 & 1 \\
\hline British Colony & 546 & 0.297 & 0.457 & 0 & 1 \\
\hline $\begin{array}{c}\text { Protestant } \\
\text { Religion }\end{array}$ & 504 & 15.577 & 24.658 & 0 & 37.8 \\
\hline $\begin{array}{c}\text { Internal } \\
\text { Conflict }\end{array}$ & 455 & 0.307 & 0.808 & 0 & 384.99 \\
\hline Open & 376 & 69.971 & 48.653 & 10.05 & 308.99 \\
\hline Open1 & 369 & 0.000 & 47.356 & -65.93 & \\
\hline
\end{tabular}

${ }^{20}$ We also test whether the effect of Protestant religion varies across time. These interactions with time are insignificant suggesting no change in the effect of this variable over the sample period. 
In Table 5 we report the sample characteristics for each of these four cultural variables as well as the measures of openness to international trade used further below. As can be seen from the table about 22 per cent of observations are from countries that have stable democracies, nearly 30 per cent have British Colonial heritage, the average ratio of Protestants is 15 per cent and most countries have no internal conflict.

Table 6: Corruption, GDP and Culture

\begin{tabular}{|c|c|c|c|c|c|c|c|}
\hline Regression No. & 8 & 9 & 10 & 11 & 12 & 13 & 14 \\
\hline $\begin{array}{l}\text { Cultural } \\
\text { Variable }\end{array}$ & $\begin{array}{c}\text { Democ- } \\
\text { racy }\end{array}$ & $\begin{array}{l}\text { British } \\
\text { Colony }\end{array}$ & $\begin{array}{c}\text { Protest- } \\
\text { ant }\end{array}$ & $\begin{array}{l}\text { Internal } \\
\text { Conflict }\end{array}$ & All & $\begin{array}{l}\text { All \& } \\
\text { threshold }\end{array}$ & $\begin{array}{c}\text { Thresh- } \\
\text { olds }\end{array}$ \\
\hline $\log (\mathrm{GDP})_{\mathrm{t}-1}$ & $\begin{array}{c}-1.082 \\
(19.03)^{* *}\end{array}$ & $\begin{array}{c}-1.425 \\
(29.06) * *\end{array}$ & $\begin{array}{c}-1.226 \\
(24.16)^{* *}\end{array}$ & $\begin{array}{c}-1.380 \\
(27.31)^{* *}\end{array}$ & $\begin{array}{c}-1.172 \\
(17.57)^{* *}\end{array}$ & $\begin{array}{c}-1.236 \\
(16.99)^{* *}\end{array}$ & $\begin{array}{c}-1.074 \\
(13.72)^{* *}\end{array}$ \\
\hline $\begin{array}{c}0.04<\mathrm{I} \\
\log (\mathrm{GDP})_{\mathrm{t}-1}\end{array}$ & & & & & & $\begin{array}{c}-0.453 \\
(3.75)^{* *}\end{array}$ & $\begin{array}{c}-0.438 \\
(4.80)^{* *}\end{array}$ \\
\hline $\begin{array}{c}\mathrm{I}>0.75 \\
\log (\mathrm{GDP})_{\mathrm{t}-1}\end{array}$ & & & & & & $\begin{array}{l}-0.020 \\
(0.75)\end{array}$ & $\begin{array}{c}-0.159 \\
(5.86)^{* *}\end{array}$ \\
\hline DEMOC & $\begin{array}{l}-1.665 \\
(8.86)^{* *}\end{array}$ & & & & $\begin{array}{c}-0.834 \\
(4.07)^{* *}\end{array}$ & $\begin{array}{c}-0.654 \\
(3.21)^{* *}\end{array}$ & \\
\hline BRITCOL & & $\begin{array}{l}-1.210 \\
(9.40)^{* *}\end{array}$ & & & $\begin{array}{c}-1.032 \\
(7.29)^{* *}\end{array}$ & $\begin{array}{c}-1.006 \\
(7.48)^{* *}\end{array}$ & \\
\hline PROD81 & & & $\begin{array}{c}-0.025 \\
(10.58)^{* *}\end{array}$ & & $\begin{array}{c}-0.018 \\
(7.58)^{* *}\end{array}$ & $\begin{array}{c}-0.017 \\
(7.03)^{* *}\end{array}$ & \\
\hline $\mathrm{IC}=1$ & & & & $\begin{array}{l}-0.593 \\
(1.55)\end{array}$ & $\begin{array}{l}-0.324 \\
(0.86)\end{array}$ & $\begin{array}{l}-0.514 \\
(1.40)\end{array}$ & \\
\hline $\mathrm{IC}==2$ & & & & $\begin{array}{l}0.116 \\
(0.46)\end{array}$ & $\begin{array}{l}0.362 \\
(2.19)^{*}\end{array}$ & $\begin{array}{l}0.217 \\
(1.40)\end{array}$ & \\
\hline $\mathrm{IC}==3$ & & & & $\begin{array}{l}-0.055 \\
(0.13)\end{array}$ & $\begin{array}{l}0.153 \\
(0.53)\end{array}$ & $\begin{array}{l}-0.045 \\
(0.16)\end{array}$ & \\
\hline Constant & $\begin{array}{c}14.370 \\
(33.08)^{* *}\end{array}$ & $\begin{array}{c}17.110 \\
(39.98)^{* *}\end{array}$ & $\begin{array}{c}15.461 \\
(38.19)^{* *}\end{array}$ & $\begin{array}{c}16.364 \\
(38.04)^{* *}\end{array}$ & $\begin{array}{c}15.490 \\
(27.53)^{* *}\end{array}$ & $\begin{array}{c}16.074 \\
(28.48)^{* *}\end{array}$ & $\begin{array}{c}14.376 \\
(25.51)^{* *}\end{array}$ \\
\hline Observations & 338 & 338 & 324 & 338 & 324 & 324 & 324 \\
\hline R-squared & 0.78 & 0.77 & 0.77 & 0.73 & 0.83 & 0.85 & 0.78 \\
\hline
\end{tabular}

In Table 6 we add to the regression each of the cultural variables in turn (regressions 8-14). As can be seen former British colonies and democratic countries are associated with lower corruption, as are countries with higher Protestant populations. The results for internal conflict suggest that countries 
with mild internal conflict actually have lower corruption than countries with no internal conflict, although this variable is not significant at standard levels. In regression 12 we add all four culture variables to the same regression and we can claim they capture different determinants of corruption. Quantifying the effect of each we find that corruption in established democracies and former British Colonies is around 2 points lower on the corruption scale 1 point lower in former British Colonies and 0.83 points lower in established democracies). This effect of level two internal conflict raises the level of corruption by 0.3 of a point in the corruption scale relative to no conflict, whereas a one standard deviation increase in the level of Protestant religion decreases corruption by close to $1 / 2$ a point. Taken together the estimated effect of these culture variables on corruption is close to the standard deviation of the corruption index.

When we control for the effect of all four culture variables and then search for thresholds in the GDP corruption relationship the results from previous regressions change. Now we find evidence of a single significant threshold, there are just two corruption-development clubs. The lower threshold, again located at the $4^{\text {th }}$ percentile [range $=4$ ] remains, while the upper threshold is removed. ${ }^{21}$ The slope parameter no longer varies significantly between the middle and upper ranges of GDP per capita. The effect of this can be seen in regression 13 when we allow the GDPpc variable to vary according to the location of the two thresholds identified previously. In regression 14 we test whether this result is due to a reduction in the number of available observations by estimating the regression for just GDP per capita over the same sample as regression 13. The effect of GDP per capita on corruption in the middle threshold now differs from that in the upper threshold and this difference is significant. When we add the four cultural variables (regression 13) and consider the same question it is no longer so. Conditional on cultural factors the relationship between corruption and development at mid-to-high income levels changes from being non-linear to linear.

Given the collective effect of these cultural variables we search whether they are driven by a single element or whether they are collectively important. We add to the regression each of the four cultural variables individually then search for thresholds in the GDP per capita variable. It would appear that two elements of the index explain the removal of the upper threshold, BRITCOL and DEMOC. When either of these variables are added to the regression only the lower threshold is identified. When the remaining cultural variables are used both the upper and lower thresholds are identified. Of the four countries that transit across the upper threshold all are former British Colonies according to the Treisman (2000) data, while two (Ireland and Israel) have had stable democracies over the period.

\footnotetext{
${ }^{21}$ A third significant threshold is again found, but the confidence interval extends from the lower threshold up to the end of the distribution.
} 


\section{Openness}

Two measures of openness are considered. The first is the lagged level of trade exposure (the ratio of exports and imports to GDP). This variable has a strong correlation with wealth and country size in a gravity equation however. To capture the disciplining effects of international trade we therefore construct a trade exposure measure net of country size and wealth. This variable (labelled open1) is constructed as the residual from a regression of trade exposure on GDP and population.

Table 7: Corruption, GDP and Openness to International Trade

\begin{tabular}{|c|c|c|c|c|}
\hline Regression No. & 15 & 16 & 17 & 18 \\
\hline $\log (\mathrm{GDP})_{\mathrm{t}-1}$ & $\begin{array}{c}-1.308 \\
(23.66)^{* *}\end{array}$ & $\begin{array}{c}-1.335 \\
(24.59)^{* *}\end{array}$ & $\begin{array}{c}-1.443 \\
(11.46)^{* *}\end{array}$ & $\begin{array}{c}-1.468 \\
(12.42)^{* *}\end{array}$ \\
\hline $0.04<\mathrm{I}<0.75$ & & & 0.413 & 0.410 \\
$\log (\mathrm{GDP})_{\mathrm{t}-1}$ & & & $(5.12)^{* *}$ & $(5.73)^{* *}$ \\
\hline $\mathrm{I}>0.75$ & & & 0.252 & 0.248 \\
$\log (\mathrm{GDP})_{\mathrm{t}-1}$ & & & $(2.80)^{* *}$ & $(3.03)^{* *}$ \\
\hline OPEN $\mathrm{t}-1$ & -0.006 & & -0.006 & \\
& $(5.29)^{* *}$ & & $(4.82)^{* *}$ & \\
\hline OPEN $1_{\mathrm{t}-1}$ & & -0.006 & & -0.007 \\
& & $(6.11)^{* *}$ & & $(5.18)^{* *}$ \\
\hline Constant & 16.142 & 15.961 & 14.453 & 14.226 \\
& $(36.20)^{* *}$ & $(36.07)^{* *}$ & $(27.39)^{* *}$ & $(27.50)^{* *}$ \\
\hline Observations & 293 & 293 & 293 & 293 \\
\hline R-squared & 0.72 & 0.72 & 0.79 & 0.79 \\
\hline
\end{tabular}

As can be seen from in regressions 15 and 16 in Table 7 both measures of openness are strongly negatively correlated with corruption. At the mean value of each of these openness indicators a one standard deviation increase in their value leads to a change in the corruption index of close to 0.3 points. This is approximately the difference in the corruption index between Denmark and Finland, who rank $1^{\text {st }}$ and $2^{\text {nd }}$ respectively on the corruption scale at the end of the sample period. The effect of openness is therefore small compared to that for GDP per capita.

These results are robust to the choice of indicator of trade openness. Given the high correlation of the openness measure controlling for the effect of wealth and country size with the trade exposure variable (correlation $=96 \%$ ) it is perhaps unsurprising that the results do not change when we use this 
alternative measure. We again find evidence of two significant thresholds, located at the $74^{\text {th }}$ and $6^{\text {th }}$ percentiles and with identical confidence intervals.

In the final regressions of Table 7 (regressions 17-18) we further demonstrate how openness does not help to explain the non-linear relationship between corruption and GDP per capita. Using the thresholds identified previously we find that although the openness variable again has a negative effect on corruption the relationship between GDP per capita and corruption still changes over the range of GDP per capita.

\section{Section 9: Conclusions}

Over the past decade there has been a renewed interest among researchers, national governments and international organisations about the causes and consequences of corrupt behaviour within government bureaucracies. This has been motivated by a strengthening conviction that good quality governance is essential for sustained economic development and that corruption in public sector is a major impediment to growth and prosperity. Recent innovations at the theoretical and empirical level have allowed this conviction to be tested formally, and there is now a large body of evidence to support the idea that corruption and development are strongly related.

In this paper we pick out three stylised facts about the relationship between corruption and development. Firstly, there is a strong negative correlation between them; secondly, that countries appear to become trapped in high corruption-low development or low-corruption-higher development clubs; and finally that the corruption levels amongst countries with intermediate levels of development display greater variability than at the ends of the income distribution. We then develop an existing model of corruption by Mauro (2004) to generate predictions consistent with these stylised facts. We have defined public sector corruption in the usual way, as the abuse of responsibility by bureaucrats in the allocation of public resources to further their own interests. As with any type of illegal or unauthorised activity however, there are costs from this deception to individuals and society on the one hand, and detection and prosecution on the other. In our case corruption results in a loss of resources available for public investment. The costs of corruption are potentially significant, especially since it takes only small changes in the growth rate to produce substantial cumulative gains or losses in output or welfare.

Our analysis respects the notion that bureaucratic corruption not only influences but is also influenced by economic development. This two-way causality is reflected in the existence of threshold effects and multiple equilibria, which allow us to explain why the incidence of corruption may vary markedly across countries, even if countries share essentially the same structural characteristics. At any point in time an economy may be located in a low development regime, a high development regime or 
an intermediate development regime. Cross-country variations in the level of corruption may occur both across and within these regimes. For example, two otherwise identical economies may end up with very different levels of corruption depending on which of the identified regimes they lie.

Finally, we then search for the location of these corruption-development clubs in the data by searching for break points in the parameter estimate between corruption and GDP per capita. We then test for the significance of the identified threshold point and provide a confidence interval around this estimate. Our empirical analysis is able to identify several culture variables that are responsible for determining the thresholds. Once we take into account the effect of stable democracies and British Colonial Heritage on corruption the higher threshold seems to disappear. These two cultural variables would appear therefore to help explain the location of the upper threshold. These two variables have themselves a significant effect on the level of corruption. Moreover this result is unique to these two cultural variables. While suggestive it is not clear why these zero/one indicator variables are such powerful predictors of the location of one of the threshold points found in the analysis. However adding other cultural variables or openness to international trade does not have the same effect. The inter-relationship between corruption, culture and development would appear to offer a potential avenue for future research and it would be interesting to test the robustness of these findings to alternative methodologies such as regression tree analysis and to alternative measures of corruption. 


\section{References}

Acemoglou, D. and T. Verdier, 1998. Property rights, corruption and the allocation of talent: a general equilibrium approach. Economic Journal, 108, 1381-1403.

Acemoglou, D. and T. Verdier, 2000. The choice between market failures and corruption. American Economic Review, 90, 194-211.

Ades, A. and R. Di Tella, 1997. The new economics of corruption: a survey and some new results. Political Studies, 45 (Special Issue), 496- 515.

Ades, A. and R. Di Tella, 1999. Rents, competition and corruption. American Economic Review, 89, 982 993.

Andvig, J.C. and K.O. Moene, 1990. How corruption may corrupt. Journal of Economic Behaviour and Organisations, 13, 63-76.

Bardhan, P., 1997. Corruption and development: a review of issues. Journal of Economic Literature, 35, 1320-1346.

Barro, R.J., 1990. Government spending in a simple model of endogenous growth. Journal of Political Economy, 98, S103-S125.

Cadot, O., 1987. Corruption as a gamble. Journal of Public Economics, 33, 223-244.

Dawid, Herbert, and Gustav Feichtinger, 1996, “On the Persistence of Corruption,” Journal of Economics, Vol. 64, No. 2, pp. 177-93.

Gatti, R. and Fisman, R., 2000. Decentralisation and corruption: evidence across countries. World Bank working paper 2290 (February).

Girma, S., Henry, M. Kneller R., and Milner C., 2003. Threshold and interaction effects in the openness-productivity growth relationship: The role of institutions and natural barriers, GEP Working paper 2003/50, The University of Nottingham.

Hansen, B. E., 2000. Sample Splitting and Threshold Estimation, Econometrica, 68, 575-603.

Huang, Peter H., and Ho-Mou Wu, 1994. "More Order Without More Law: A Theory of Social Norms and Organizational Cultures," Journal of Law, Economics, and Organization, Vol. 10, No. 2, pp. 390 406.

Jain, A.K. (ed.), 1998. The Economics of Corruption. Kluwer Academic Publishers, Massachusettes.

Knack, S. and P. Keefer, 1995. "Institutions and Economic Performance: Cross-Country Tests Using Alternative Institutional Measures." Economics and Politics, 7 (3), 207-27. 
La Porta R., Lopez-de-Silanes F., Shlieifer, A., and Vishny, R.W., 1999. The Quality of Government, The Journal of Law, Economics and Organiszation, 15, 222-279.

Mauro, P., 1995. Corruption and growth. Quarterly Journal of Economics, 110, 681-712.

Mauro, P., 2004. Persistence of Corruption and Slow Economic Growth. IMF Staff Papers, Vol. 51, No. $1,2004$.

Murphy, Kevin M., Andrei Shleifer, and Robert W. Vishny, 1993. 1993, "Why Is Rent-Seeking So Costly to Growth?" American Economic Review, Papers and Proceedings, Vol. 83, No. 2, pp. 409-14.

Papageorgiou, C., 2002 Trade as a threshold variable for multiple regimes, Economics Letters, 77, 85-91..

Persson, T., Tabellini, G., and Trebbi, F., 2001. Electoral Rules and Corruption, NBER Working Paper 8154.

Putnam, R.D., 1993. Making Democracy Work: Civic Traditions in Modern Italy, (Princeton, New Jersey: Princeton University of Press.

Romer, P., 1986: "Increasing Returns and Long Run Growth", Journal of Political Economy, 94, 5 (October), $1002-1037$.

Sah, R.K., 1991. Social Osmosis and Patterns of Crime. Journal of Political Economy, 99, 1272 - 1295.

Strand, H., Wilhelmsen, L. and Gleditch, N.P., 2003. Armed Conflict Dataset Codebook. International Peach Research Institute, Department of Peace and Conflict Research, Uppsala University, Sweden.

Tanzi, V. and H. Davoodi, 1997. Corruption, public investment and growth. IMF Working Paper No.WP/97/139.

Tirole, J. 1996. A Theory of Collective Reputation (with applications to the persistence of corruption and to farm quality). Review of Economic Studies, 63, 1 - 22.

Treisman, D., 2000. The causes of corruption: a cross-national study. Journal of Public Economics, 76, 399457.

Wei, S., 2000. How taxing is corruption on international investors? Review of Economics and Statistics, 82, 1-11.

Winters, L.A., 2004. 'Trade liberalisation and economic performance: an overview', The Economic Journal, Vol. 114. No. 493, F4-F21. 